\title{
Information and Strategies for Chinese Micro and Small Enterprises in Crowd funding Mode
}

\author{
Bao Zheshi ${ }^{1, a}$ \\ ${ }^{1}$ Business School of Hohai University Nanjing 210000, China \\ abhxbzs@hhu.edu.cn
}

Keywords: crowdfunding; financing; M\&S enterprises; information; strategy

\begin{abstract}
As the rise of Internet finance, more and more micro and small(M\&S) enterprisesapply new methods toovercome shortage of funds. Crowdfunding is one of them. This methodis consideredas an effective way to improve the efficiency of financing and alleviatethe information asymmetry between investors and financiers. To many M\&Senterprises, especially those ininitial stages of pioneering, crowdfunding is both an opportunity and a challenge. Throughthisnew and openfinancing mean, exploring valuable information, transforminginformation into competitive intelligence and drawing up a reasonable strategy arethree important stepsfor seizing business opportunities.
\end{abstract}

\section{Introduction}

Crowdfunding is a financing mode that accumulates public funds through Internet platforms to start someone's business. Since the first website of crowdfunding-Kickstarteremerged in 2009 in America, this financing mode is experiencing a rapid development. According to the forecast of World Bank, by the year 2025, the global average annual market size of public fundingwill reach $\$ 96$ billion. ${ }^{[1]}$ In China, only in the first half year of 2014, 1423 cases of public funding were happened, and RMB 189.71 million was collected. ${ }^{[2]} \mathrm{As}$ a transparent, open and efficient financing mode, the rise of crowd funding is a promotion and incentive for M\&Senterprises that are in the initial stage of pioneering and lack of funds. For Micro and small enterprises, besides seizing the opportunity of financing, they should take advantage of the open and transport financing process to discover the information of customers' preference, the trend of market and the strategies of their competitors, and then strive for an invincible position in the fierce competition for themselves.

\section{A briefintroduction of crowdfunding}

Connotation and mode. The rise of Crowdfunding is in the United States in 2009. Generally, the so-called crowdfunding refers to financing activities thatrequirepublic participation. Under the background of Internet Age, the connotation of crowd funding is becoming more and more specific. Now this phrase mainly describes behaviors of some individuals or enterprisesthatcollect small amount of moneyonline from the public for starting their projects. The methods include appealing for donation, purchasing in advance, equity transferetc. For manyM\&S enterprises, which are lack of venture capital, this new mode can provide an efficient and feasible financing approach. In addition, mostwebsites or platformsof crowdfunding are usually open, transparent and easy to access,so they can be seen as windowsfor these enterprises to present and display somenew ideasor creative products.

As far as it is concerned, there are three main modes of crowdfunding for Chinese enterprises and individuals. Table 1 lists the financing forms, channels of reward and representative platforms of them. The first mode is donation. For instance, the crowdfunding platform of JD Finance and Demo Hour.com and many other related websites provide donation channels for people who are interested in these projects and willing to support them. In this mode,social participation spirit plays a very important role. Ordanini. A(2011) once made an experience regarding the participate motivation of crow funding. The result demonstrate that sometimes people are willing to take part 
in social activities to help others who need help, because this can bring them a sense of achievement.

${ }^{[3]}$ Almost all websites of crowdfundingencouragepeople to donate, and some of them hold lottery activities to reward and attract donators.

The second mode is advance booking. In this mode, when one project is just a conception or still in the tentative stage, enterprises can present them on the websites of crowdfunding to attract potential customers and investors. If someone is interested in this project, he could purchase at a discount price in advance. When the finished products are manufactured, he will receive one. This mode helpsM\&S enterprises alleviate the shortage of funds. Furthermore, in this way, the whole process of financing is equivalent to a process of purchasing, sothese enterprises can avoid supervisionsfromofficialfinancial institutions. This brings great convenience for business behaviors. The representative website is ZhongChou.com.

The third mode of crowdfunding is equity-based. In this mode, enterprisestransfer a certain percentage of shareholding to investors in exchange forstart-up capital.The key to judge the attributeof a project is tosurveyits return methods. If one enterprisepromises to give investors a part of shareholdingaccording to the amount of investment and share risk with enterprises, this kind of crowdfunding can be called equity-based. Such projects usually require comparative larger amount of investment and high reward, but investors have to suffer higher risk. The representative websites are DaJiaTou.com and RenRenTou.com.

Table 1Three modes of crowdfunding

\begin{tabular}{|c|c|c|c|c|}
\hline Mode & Form & & Reward & $\begin{array}{l}\text { Representative } \\
\text { platforms }\end{array}$ \\
\hline $\begin{array}{c}\text { Donation } \\
\text { sponsorship }\end{array}$ & Free donation & & No fixed form & $\begin{array}{l}\text { Most websites of } \\
\text { Crowd-funding }\end{array}$ \\
\hline Booking in advance & $\begin{array}{l}\text { Preselling } \\
\text { preferential price }\end{array}$ & With & Finishedproducts & $\begin{array}{l}\text { ZhongChou.com, JD } \\
\text { Finance }\end{array}$ \\
\hline equity-based & Equity transfer & & Equity and bonus & $\begin{array}{l}\text { DaJiaTou.com, } \\
\text { RenRenTou.com }\end{array}$ \\
\hline
\end{tabular}

Analysis of itspopulation.Crowdfunding quickly accepted by $M \& S$ enterprises in China is because it alleviates the financing difficulty of private enterprises especially those inprimary stage. Some of these enterprises master core technology, but they are lack of business records. Besides, the financial information of themdoes notmeet the requirementsof Chinese banks, and never open to the public. Banks cannot judge the repaying ability of these enterprises, so they often refuse to serve a loan. Because of this information asymmetry, many M\&Senterprises cannot get funds from traditional channels. (Fig. 1 presents two different channls.)

The rising of crowdfunding provides a new method of financing. M\&Senterprises can skip banks and directly finance from the public. Through platforms (websites) of crowdfunding, these enterprises can introduce the plan, design and profit potential of projects. Moreover, they are also required listingrisks and challenges. Through these information, the public selectinvestment project by themselves. If one project fails to achieve the finance target set by websites crowdfunding, it will be judged as an inferior project, and the process of financing is require be terminated. Intermediary platforms will send all already raised fund back to investors. This open and transparentfinancing method realizes the direct match between investors and enterprises and significantly improve the financing efficiency. 


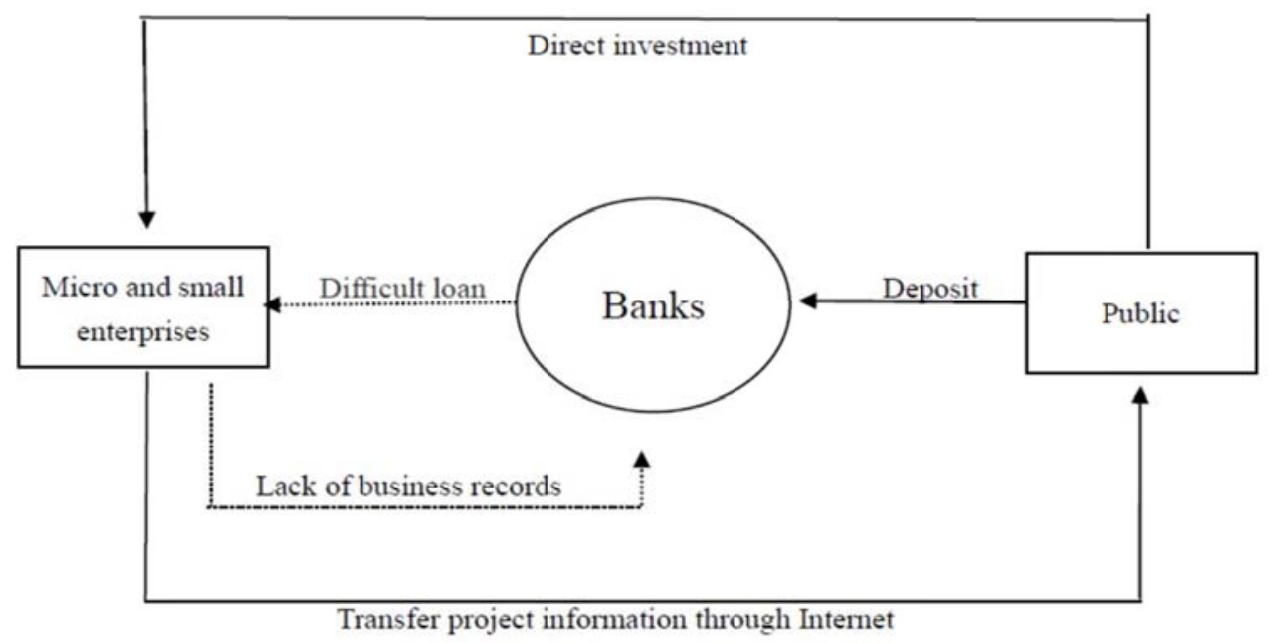

Fig. 1 Two different channls of finance

\section{Acquisition and Utilization of Information}

Besides the convenient and efficient financing channel, crowdfunding also bring overwhelming information and knowledge resource for enterprises and individuals. How to distinguish them and translate them into valuable information is necessary for enterprises to research industry, market, competitors and consumers.

Carrier and bridge of information. In the process of crowdfunding, websites are important platforms to maintain $M \& S$ enterprises and investors. They work as information hubs. Through these platforms, enterprises have a chance topresent their ideas, conception, and achievement of projects with multimedia technology. Furthermore, most crow-funding websites will timely release related data. For instance, the ZhongChou.Com will list financing amount, the number of supporters, financing progress and investors' comment of every project. This series of data triggers the mass screen mechanism to help investors judge the risk of every project and then optimize investment decisions. Meanwhile, micro and small enterprises could take advantage of these platforms to collect the information of potential customers. They will quickly judge the population and prospect of their projects. In addition, compared to the similar projects online, these they can easily find the strengths and weaknesses.

For another, websites of crowdfundingusually undertake the function ofsupervising. Usually, the investment from the public is indirectly received by financing enterprises, and websites act as third-party platforms to temporary storage investors' fund. If one project raises enough amount of fund before the deadline, the enterprise will be able to get the public's investment to start the project, or allfund have raised will be returned to investors. This rule reduces the risk of investors to a certain extent.

Screening of entrepreneurial information. As a carrier and bridge of information, crowd funding websitescan greatly avoid information asymmetry, and for micro and small enterprises, how to utilize this information resource in their initial stages is extremely important. When an enterprise plans to launch a new project, it can make fully use of all information presented on these websites. After data analysis and collection, enterprises can approximately estimate the amount of competitors, industry barriers, stage of development, future potential etc. If projects or conceptions, which $M \& S$ enterprises intend to promote, have beenmassively emerged on the websites of crowdfunding, it means suffering a highly competitive field. So all original financing plans are required togive up, thereby avoid the potential risk. Furthermore, by analyzing similar projects on the websites, M\&S enterprises can also predict the financing schedule, popularity and promotion mode of their own projects. Overall, websites of crowdfunding indicates of similar project andhelp enterprisesdecide whether to get involved in target field. In addition, through browsing all related 